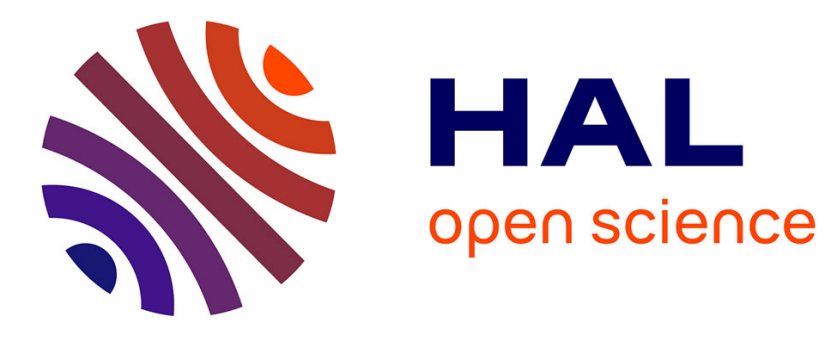

\title{
Lysine-specific acetylated proteome from the archaeon Thermococcus gammatolerans reveals the presence of acetylated histones
}

\author{
Béatrice Alpha-Bazin, Aurore Gorlas, Arnaud Lagorce, Damien Joulié, \\ Jean-Baptiste Boyer, Murielle Dutertre, Jean-Charles Gaillard, Anne Lopes, \\ Yvan Zivanovic, Alain Dedieu, et al.
}

\section{To cite this version:}

Béatrice Alpha-Bazin, Aurore Gorlas, Arnaud Lagorce, Damien Joulié, Jean-Baptiste Boyer, et al.. Lysine-specific acetylated proteome from the archaeon Thermococcus gammatolerans reveals the presence of acetylated histones. Journal of Proteomics, 2021, pp.104044. 10.1016/j.jprot.2020.104044 . hal-03010126

\section{HAL Id: hal-03010126 https://hal.science/hal-03010126}

Submitted on 24 Mar 2021

HAL is a multi-disciplinary open access archive for the deposit and dissemination of scientific research documents, whether they are published or not. The documents may come from teaching and research institutions in France or abroad, or from public or private research centers.
L'archive ouverte pluridisciplinaire HAL, est destinée au dépôt et à la diffusion de documents scientifiques de niveau recherche, publiés ou non, émanant des établissements d'enseignement et de recherche français ou étrangers, des laboratoires publics ou privés. 


\title{
Lysine-specific acetylated proteome from the archaeon Thermococcus gammatolerans reveals the presence of acetylated histones
}

Béatrice Alpha-Bazin a, Aurore Gorlas ${ }^{\mathrm{b}}$, Arnaud Lagorce ${ }^{\mathrm{b}, \mathrm{c}}$, Damien Joulié ${ }^{\mathrm{a}}$, Jean-Baptiste Boyer ${ }^{\text {a }}$, Murielle Dutertre ${ }^{\mathrm{b}}$, Jean-Charles Gaillard ${ }^{\mathrm{a}}$, Anne Lopes ${ }^{\mathrm{b}}$, Yvan Zivanovic ${ }^{\mathrm{b}}$, Alain Dedieu $^{\text {a }}$, Fabrice Confalonieri ${ }^{\mathrm{b}, 1}$, Jean Armengaud ${ }^{\mathrm{a},{ }^{*}, 1}$

${ }^{a}$ Université Paris-Saclay, CEA, INRAE, Département Médicaments et Technologies pour la Santé (DMTS), SPI, 30200 Bagnols-sur-Cèze, France

${ }^{\mathrm{b}}$ Université Paris-Saclay, CEA, CNRS, Institute for Integrative Biology of the Cell (I2BC), 91198 Gif-sur-Yvette, France

c IHPE, Université de Montpellier, CNRS, Ifremer, Université de Perpignan, Via Domitia, Perpignan, France

* Corresponding author : jean.armengaud@cea.fr (J. Armengaud).

${ }^{1}$ These two co-authors should be considered as co-Last author.

\begin{abstract}
Thermococcus gammatolerans EJ3 is an extremophile archaeon which was revealed as one of the most radioresistant organisms known on Earth, withstanding up to $30 \mathrm{kGy}$ gamma-ray radiations. While its theoretical proteome is rather small, T. gammatolerans may enhance its toolbox by post-translational modification of its proteins. Here, we explored its extent of $\mathrm{N} \varepsilon-$ acetylation of lysines. For this, we immunopurified with two acetylated-lysine antibodies the acetylated peptides resulting from a proteolysis of soluble proteins with trypsin. The comparison of acetylated proteomes of two archaea highlights some common acetylation patterns but only 4 out of 26 orthologous proteins found to be acetylated in both species, are acetylated on the same lysine site. We evidenced that histone $\mathrm{B}$ is acetylated in $T$. gammatolerans at least at two different sites (K27 and K36), and a peptide common at the Cterminus of histones A and B is also acetylated. We verified that acetylation of histones is a common trait among Thermococcales after recording data on Thermococcus kodakaraensis histones and identifying three acetylated sites. This discovery reinforces the strong evolutionary link between Archaea and Eukaryotes and should be an incentive for further investigation on the extent and role of acetylation of histones in Archaea.

Significance: Acetylation is an important post-translational modification of proteins that has been extensively described in Eukaryotes, and more recently in Bacteria. Here, we report for the first time ever that histones in Archaea are also modified by acetylation after a systematic survey of acetylated peptides in Thermococcus gammatolerans. Structural models of histones $\mathrm{A}$ and $\mathrm{B}$ indicates that acetylation of the identified modified residues may play an important role in histone assembly and/or interaction with DNA. The in-depth protein acetylome landscape in T. gammatolerans includes at least 181 unique protein sequences, some of them being modified on numerous residues. Proteins involved in metabolic processes, information storage and processing mechanisms are over-represented categories in this dataset, highlighting the ancient role of this protein post-translational modification in primitive cells.
\end{abstract}

\section{Keywords}

Proteome ; Post-translational modification ; Acetylome ; Archaea ; Histone 


\section{Introduction}

Reversible protein $N^{\varepsilon}$-Lysine acetylation, a post-translational modification (PTM), was first discovered on histones [1,2]. Since these first studies, lysine acetylation has been recognized as an abundant and important PTM and found conserved in the three domains of life $[3,4]$. It influences a wide variety of essential biological processes [5]. In prokaryotes, the reversibility of this PTM is catalyzed by a KAT family acetyltransferase and different deacetylases (KDACs, sirtuins or serine hydrolases). In addition, a non-reversible $N^{\alpha}$-lysine acetylation catalyzed by $\mathrm{N}$-terminal acetyltransferases may also occur at the $\mathrm{N}$-terminal of proteins [6,7]. However, the functional implication of $N^{\alpha}$-lysine acetylation remains unclear for prokaryotes $[8,9]$.

Based on shotgun proteomics, in-depth exploration of the acetylome from several organisms belonging to the different domains of life has been reported [8]. In these studies, most bacterial acetylated proteins are involved in metabolic processes, particularly the control of central metabolism, but also in transcription, translation, virulence, adaptation, and stress responses [10-12]. All these results indicate that protein acetylation is a common trait in bacteria and is involved in a broad range of cellular functions.

While acetylomes in Bacteria have been well documented, only a few studies have been reported for Archaea. A [2Fe-2S] ferredoxin from Halobacterium salinarum (previously named Halobacterium halobium) [13] and the chromatin protein Alba (standing for "acetylation lowers binding affinity") from Sulfolobus solfataricus [14] were the first archaeal proteins identified with an internally acetylated lysine. The residue 16 of Alba can be acetylated by the PatA acetyltransferase and deacetylated by an archaeal Sir2 homolog, thereby mediating transcriptional repression [14]. It has been suggested that the acetylation state of Alba influences the level of chromatin packaging in Sulfolobus [4]. Nevertheless, recent studies have shown that this lysine residue is not acetylated but extensively methylated [15]. The same applies for the Alba homolog from the closely-related archaeon Sulfolobus islandicus [7]. The substitution of this lysine by an arginine residue did not modify cell growth but triggered transcription of a few genes [15]. Recent surveys of different archaeal acetylomes from Halobacterium salinarum, Natronomonas pharaonis, Haloferax volcanii and Sulfolobus islandicus revealed that $\mathrm{N}^{\alpha}$-lysine acetylation is an abundant modification in these organisms and that methylation on lysine side chains is the most frequent PTM found in S. islandicus $[7,16,17]$. By contrast, using an immunoaffinity enrichment and tandem mass spectrometry, Liu et al. [18] identified 1017 acetylated $\mathrm{N}^{\varepsilon}$-lysine sites in 643 proteins from Haloferax mediterranei. Among the proteins detected as acetylated, some enzymes are involved in glycolysis, tricarboxylic acid (TCA) cycle, poly(3-hydroxybutyrate-co-3-hydroxyvalerate) biosynthesis from acetyl-CoA and propionyl-CoA. Many other proteins are involved in key biological processes, such as transcription and replication. Interestingly, the mutation of acetylated site in $H$. mediterranei replication initiation protein Cdc6A destroyed the Autonomous Replicating Sequence (ARS) activity of its adjacent origin oriC1 [18].

Thermococcus gammatolerans EJ3 was isolated from samples collected from hydrothermal chimneys located in the mid-Atlantic Ridge and the Guyamas basin [19]. T. gammatolerans is one of the most radioresistant organisms known on Earth, as it withstands 5 $\mathrm{kGy}$ of radiation without any detectable lethality [20]. T. gammatolerans genome is composed of a circular chromosome of $2.045 \mathrm{Mbp}$ without any extra-chromosomal element, coding for 2157 proteins [21]. T. gammatolerans was described as an obligatory anaerobic heterotroph organism that grows optimally at $88{ }^{\circ} \mathrm{C}$ in the presence of sulfur or cystine on yeast extract, tryptone and peptone, producing $\mathrm{H}_{2} \mathrm{~S}$. Here, we established the protein lysine-specific acetylome survey from exponentially growing phase $T$. gammatolerans cells taking into account acetylated-lysine peptide enrichment by two different antibodies. We detected in $T$. 
gammatolerans $316 \mathrm{~N}^{\varepsilon}$-Lysine peptides, representing 338 different acetylation sites, from 181 unique proteins. We report here for the first time that Thermococcus histones may be acetylated on different positions.

\section{Materials and methods}

\subsection{Strains, media and growth conditions}

T. gammatolerans EJ3 was grown in serum bottles under anaerobic conditions at $85^{\circ} \mathrm{C}$ in complex organic medium (VSM) supplemented with $S^{\circ}(2 \mathrm{~g} / \mathrm{l})$ as previously described [20]. Serum bottles were inoculated at a cellular density of $5 \times 10^{5}$ cells $/ \mathrm{ml}$ and incubated at $85^{\circ} \mathrm{C}$ for $16 \mathrm{~h}$. Cells were harvested at a cellular density of $8-9 \times 10^{7}$ cells $/ \mathrm{ml}$ corresponding to the transition phase between the late exponentially growing phase and the beginning of the stationary phase.

\subsection{Protein extraction}

A lysis buffer containing a complete, EDTA-free, protease inhibitor cocktail (Roche, 1 tablet per $50 \mathrm{ml}$ ), phosphatase inhibitor cocktails 2 and 3 (Sigma-Aldrich, 1: $100 \mathrm{vol} / \mathrm{vol}$, each), $8 \mathrm{M}$ urea, $75 \mathrm{mM} \mathrm{NaCl}, 50 \mathrm{mM}$ Tris ( $\mathrm{pH} 8.2$ ), $50 \mathrm{mM} \beta$-glycerophosphate, $1 \mathrm{mM}$ sodium orthovanadate, $10 \mathrm{mM}$ sodium pyrophosphate, $1 \mathrm{mM} \mathrm{MgCl}$, and Benzonase $25 \mathrm{KU}$ (1: 10,000, $\mathrm{vol} / \mathrm{vol}$ ) was prepared. Four independent biological samples were prepared as follows. $T$. gammatolerans cells were resuspended in $3.5 \mathrm{ml}$ of lysis buffer per gram of cells, disrupted by sonication and centrifugated at $13,000 \mathrm{~g}$ for $20 \mathrm{~min}$ at $4^{\circ} \mathrm{C}$. Supernatants were collected, and protein concentrations were measured using the Bradford method.

\subsection{Immunodetection of acetylated lysines by Western Blotting}

Each protein lysate $(20 \mu \mathrm{g})$ was resolved by SDS-PAGE on a $4-12 \% \mathrm{Nu}$-PAGE gel in $5 \%$ MOPS buffer (Novex) and transferred to a $0.45-\mu$ m polyvinylidene difluoride membrane (Thermo Scientific Pierce) by means of a MiniTrans-Blot, Electrophoretic Transfert Cell (BioRad). Blocking of non-specific binding was achieved by placing the membrane in a $4 \%(w / v)$ BSA solution in TBST buffer (Trizma Base $25 \mathrm{mM}$, Glycine $192 \mathrm{nM}$, EtOH 10\%, pH 8.5, Tween $200.1 \%$ ) for $6 \mathrm{~h}$. Acetylated lysines were detected using either an anti-acetyl-lysine rabbit polyclonal antibody (ICP380, ImmuneChem) at dilution 1:1000 or an anti-acetyl-lysine rabbit monoclonal antibody (Cell Signaling Technologies) at dilution 1:4000 overnight at $4^{\circ} \mathrm{C}$. After washing with TBST buffer three times for $5 \mathrm{~min}$, an horseradish peroxidase conjugated anti-rabbit IgG (dilution 1:2000) was added for $1 \mathrm{~h}$ incubation at room temperature. All antibody solutions were prepared in TBST buffer with $4 \%$ bovine serum albumin. Immobilon Western Chemiluminescent HRP Substrate (Millipore) was used for membrane revelation. Finally, detection was performed by means of a $45 \mathrm{~s}$ exposure in a Hyperprocessor developing apparatus (Amersham).

\subsection{Microwave-assisted in solution proteolysis}

For each T. gammatolerans proteome sample, $0.8 \mathrm{mg}$ of protein material per microcentrifuge tube was reduced by $10 \mathrm{mM}$ dithiothreitol (DTT) at $37^{\circ} \mathrm{C}$ for $1 \mathrm{~h}$. A $50 \%$ formic acid aqueous solution was then added at a $6 \%(\mathrm{v} / \mathrm{v})$ final concentration. Tubes were sealed, placed in a glass water bath, and exposed to $750 \mathrm{~W}$ microwave energy in an oven for $2.5 \mathrm{~min}$. After denaturation the tubes were placed on melting ice. A volume of $0.5 \mathrm{M}$ Tris-Base was added per tube to bring $\mathrm{pH}$ to $8.0-8.5$. The fractions were then alkylated by $20 \mathrm{mM}$ iodoacetamide by incubation for $30 \mathrm{~min}$ in the dark at room temperature. Proteolysis was performed by adding trypsin solution $(0.5 \mu \mathrm{g} / \mu \mathrm{l}$ in $0.01 \%$ trifluoroacetic acid (TFA)) at 2:100 enzyme to protein mass ratio $(w / w)$ and an overnight incubation at $37^{\circ} \mathrm{C}$. Proteolysis was 
stopped by lowering the $\mathrm{pH}$ to 4.0 with a $50 \%$ formic acid aqueous solution. The proteolysis yields were monitored by SDS-PAGE carried out on a 4-12\% Bis-Tris gradient NuPAGE gel run as previously described [22]. Tryptic digests were desalted using Sep-Pak Plus Cartridge $\mathrm{C} 18$ (Waters), eluted in $65 \% \mathrm{CH}_{3} \mathrm{CN} / 35 \% \mathrm{H}_{2} \mathrm{O} / 0.1 \%$ TFA. The eluates were dried using a SpeedVac and then dissolved in $50 \mathrm{mM}$ Tris- $\mathrm{HCl}$ buffered at $\mathrm{pH} 8.0$, and containing $150 \mathrm{mM}$ $\mathrm{NaCl}$ and $1 \mathrm{mM}$ EDTA (ETN buffer) at $5 \mathrm{mg}$ protein digest $/ \mathrm{ml}$.

\subsection{Enrichment of acetylated-lysine peptides by immunocapture}

Two different antibodies were used to enrich acetylated-lysine containing peptides. An affinity-purified anti-acetyl-lysine antibody was used from a commercial preparation (ICP0388; ImmunoChem Pharmaceuticals Inc.) consisting of the pan-specific antibody covalently bound to agarose beads. Tryptic digests were added to $40 \mu \mathrm{l}$ of pan antibody-agarose beads and incubated overnight at $4^{\circ} \mathrm{C}$. The beads were washed three times with ETN buffer consisting of $50 \mathrm{mM}$ Tris- $\mathrm{HCl}(\mathrm{pH} 8.0), 100 \mathrm{mM} \mathrm{NaCl}$, and $0.5 \% \mathrm{NP} 40$. The bound peptides were eluted from the beads with $2 \times 30 \mu \mathrm{l}$ of Glycine- $\mathrm{HCl} 50 \mathrm{mM}, \mathrm{pH} 2.5$. The acetylated lysine monoclonal antibody (\#9814; Cell Signaling Technologies) was incubated with Protein A agarose beads (ICP1001; ImmuneChem Pharmaceuticals Inc.) for $4 \mathrm{~h}$ at $4^{\circ} \mathrm{C}$. Supernatant was removed and the beads were washed twice with ETN buffer. Tryptic digest was then added to these beads and incubated overnight at $4 \circ \mathrm{C}$. After washing three times with ETN buffer the bound peptides were eluted from the beads with $2 \times 30 \mu \mathrm{l}$ of Glycine- $\mathrm{HCl} 50 \mathrm{mM}, \mathrm{pH} 2.5$ buffer. Combined eluates were desalted on ZipTip C18 (Millipore) according to the manufacturer's instructions and dried in a SpeedVac. Immuno-enriched lysine acetylated peptides were solubilized in $40 \mu 1$ of TFA $0,1 \%$ prior to nano-liquid chromatography-tandem mass spectrometry (nanoLCMS/MS) analysis.

\subsection{NanoLC-MS/MS analysis of the immune-enriched peptides}

The identification was performed by nanoLC-MS/MS using a LTQ-Orbitrap XL hybrid mass spectrometer (ThermoFisher) coupled to an UltiMate 3000 LC system (Dionex-LC Packings), essentially as previously described [23]. Immune-enriched peptides (10 $\mu 1)$ were loaded and desalted online on a reverse phase Acclaim Pepmap $100 \mathrm{C} 18$ precolumn ( $5 \mu \mathrm{m}$ bead size, $100 \AA \AA$ pore size, $300 \mu \mathrm{m}$ i.d. $\times 5 \mathrm{~mm}$; LC Packings). Peptides were resolved on a nanoscale Acclaim Pepmap100 C18 reverse phase capillary column ( $3 \mu \mathrm{m}$ bead size, $100-\AA$ pore size, 75 $\mu \mathrm{m}$ i.d. $\times 15 \mathrm{~cm}$; LC Packings) operated at a flow rate of $0.3 \mu 1 . \mathrm{min}^{-1}$ along a $120-\mathrm{min} \mathrm{CH}_{3} \mathrm{CN}$ gradient from 0 to $40 \%$ solvent $\mathrm{B}\left(100 \% \mathrm{CH}_{3} \mathrm{CN}, 0.1 \% \mathrm{HCO}_{2} \mathrm{H}\right)$, solvent A being $0.1 \%$ $\mathrm{HCO}_{2} \mathrm{H}$. Full-scan mass spectra were measured from $\mathrm{m} / z, 300$ to 1800 with the LTQ-Orbitrap XL mass spectrometer operated in the data-dependent mode. A TOP7 strategy was used, consisting in a very accurate scan in the Orbitrap analyzer (30,000 resolution; internal calibration) while the 7 most abundant precursor ions detected in the Orbitrap pre-scan were fragmented in the linear ion trap with dynamic exclusion of previously selected ions. A normalized collision energy of $35 \%$ was used for the fragmentation.

\subsection{NanoLC-MS/MS characterization of chromatin-bound proteins}

The detection of peptide mixtures resulting from trypsin digestion of chromatin proteins extracted from T. kodakaraensis was performed on a Q-Exactive HF mass spectrometer (ThermoFisher) coupled to an UltiMate 3000 LC system (Dionex-LC Packings) operated at a flow rate of $0.3 \mu 1 . \mathrm{min}^{-1}$ essentially as described [24]. Peptides were resolved on a $50 \mathrm{~cm}$ nano scale AcclaimPepmap100 C18 reverse phase capillary column with the same 120 min gradient described here above. A Top 20 strategy was applied in data dependent acquisition mode. Full scan mass spectra were acquired from $\mathrm{m} / z, 350$ to 1800 with an AGC target set at $3 \times 10^{6}$ ions and a resolution of 60,000 . MS/MS scan was initiated when the ACG target reached $10^{5}$ ions 
with a threshold intensity of $1.7 \times 10^{5}$ and potential charge states of $2+$ and $3+$. Ion selection was performed applying a dynamic exclusion window of $10 \mathrm{~s}$.

\subsection{Peptide-to-MS/MS spectrum assignation}

Peak lists were generated as described previously [23]. Using the MASCOT (2.2.06) search engine (Matrix Science), MS/MS spectra were searched against the protein coding sequences from T. gammatolerans (2157 entries totaling 636,564 residues, [21]). MS/MS assignments were performed with the following parameters: i) mass tolerance of $5 \mathrm{ppm}$ on the parent ion, ii) mass tolerance of 0.5 or 0.02 Da for fragment ions from MS/MS acquired with the LTQ orbitrap or the Q Exactive HF, respectively; iii) carbamidomethylated Cys $(+57.0215)$ as static modifications; and iv) oxidized methionine (+15.9949) and acetylation of amino group $(+42.0105)$ as variable modification. The maximum number of missed cleavages was set at 2 . All peptide matches with a peptide score with a $p$-value below 0.05 were filtered.

\subsection{Extraction of chromatin proteins from T. kodakaraensis}

T. kodakaraensis cells were cultured at $85^{\circ} \mathrm{C}$ in VSM medium supplemented with sodium butyrate $(\mathrm{NaBu})$ at $5 \mathrm{mM}$. Cultures in mid-exponential phase or late stationary phase were centrifuged at $4000 \mathrm{~g}$ for $20 \mathrm{~min}$. The pellets were treated following the protocol developed by Maruyama et al. [25] with slight modification. Briefly, cells were frozen at $-80^{\circ} \mathrm{C}$ for $1 \mathrm{~h}$ and then lysed in a solution containing $25 \mathrm{mM}$ HEPES (pH 7.0), $15 \mathrm{mM} \mathrm{MgCl}_{2}, 100 \mathrm{mM} \mathrm{NaCl}, 0.4$ M Sorbitol, $0.5 \%$ Triton $\mathrm{X} 100$, and $0.5 \mathrm{mM} \mathrm{NaBu}$ during $20 \mathrm{~min}$ at $4^{\circ} \mathrm{C}$. The lysates were centrifuged at $2350 \mathrm{~g}$ for $20 \mathrm{~min}$. The resulting pellets containing the chromatin associated proteins were washed with lysis buffer, then centrifuged at $12,000 \mathrm{~g}$ for $20 \mathrm{~min}$ and stored at $-20^{\circ} \mathrm{C}$. Chromatin associated proteins were then resolved by SDS-PAGE on NuPAGE $4-12 \%$ Bis-Tris gel (Thermofisher) with MES as running buffer (Invitrogen). Gels were stained with Coomassie Blue. After destaining, the low-molecular weight band of each gel lane, containing histone-sized proteins of the sample, was sliced. The resulting polyacrylamide gel pieces were processed by in-gel proteolysis with trypsin Gold (Promega) in the presence of $0.01 \%$ ProteaseMax additive (Promega), as previously described [26]. The resulting peptide digests were analyzed by nanoLC-MS/MS.

\subsection{T. gammatolerans and $H$. mediterranei orthologous protein inference}

T. gammatolerans (NC_012804) and H. mediterranei (NC_017941) protein coding sequences were all blasted without SEG filtering (BLASTP) against each other. Among the various alignment statistics, bit score was chosen in order to obtain significant similarity information. Hence, maximum bit score (max bitscore) was defined as the bit score obtained by aligning one sequence with itself, setting the $100 \%$ of max bitscore value. Plotting the distribution of percent of max bitscore (\% max bitscore) obtained by BLASTing one population of sequences against another (not shown), allows generally to identify regions of orthologous and paralogous (multicopy genes, gene families) peaks on the distribution plot. A threshold of $35 \%$ for (reciprocal, in both direction) max bitscore to accept orthologous relation between two sequences was defined. Sequence pairs of orthologous proteins, as defined above, from $T$. gammatolerans and $H$. mediterranei, in which at least one member is known to be acetylated, were aligned with MultAlin [27]. Shared positions of un-acetylated, hemiacetylated (lysine residue position conserved in two homologous proteins only found acetylated in one protein) and acetylated lysine residues at equivalent position on both protein sequences were identified.

\subsection{Histone structural models}

Structural models of homodimers (HTkA/HTkA and HTkB/HTkB) were generated with Swiss-Model [28] using as template the X-ray structure of HPhA from P. horikoshii, (PDB 
code: 1ku5). The ratios of sequence identity shared by HPhA with HTkA and HTkB are $89 \%$ and $85 \%$, respectively. The quality of both models is very high (GMQE score of 0.94 and QMEAN score of 2.01). In order to generate a model of the histone superhelix (involving either homodimers of HTkA or HTkB), the 3D models of HTkA or HTkB homodimers were aligned onto the two layers of the HMfB superhelix from $M$. fervidus (i.e. six consecutive homodimers of HMfB; PDB code: 5t5k). The sequence identity ratio between histones from M. fervidus and T. kodakarensis is $54 \%$. The RMSD after superposition of homodimers of HMfB with either homodimers of HTkA or HTkB is $0.73 \AA$ in both cases.

\subsection{2. $M S / M S$ data repository}

The mass spectrometry proteomics data have been deposited to the ProteomeXchange Consortium via the PRIDE [29] partner repository with the dataset identifier PXD016987 and https://doi.org/10.6019/ PXD016987.

\section{Results and discussion}

\subsection{Massive lysine acetylation evidenced in T. gammatolerans by immunodetection}

We first investigated the occurrence of acetylation on proteins by immunodetection on Western blot using two antibodies raised against acetylated lysines. Fig. 1 shows the westernblot immunostaining of proteins extracted from T. gammatolerans cells. Acetylated proteins were revealed with either acetylated-lysine rabbit polyclonal antibodies (Fig. 1, lanes 1-3) or an acetylated-lysine rabbit monoclonal antibody (Fig. 1, lanes 4-6). In both cases, different bands spanning a wide mass range of proteins were detected, signing massive lysine acetylation of proteins. Noteworthy, the polyclonal antibodies revealed the presence of four main protein bands, abundantly detected (Lanes 1 and 2), while the monoclonal antibody did not reveal strong differences between protein profiles.

\subsection{Shotgun proteomic screening of lysine acetylome}

A shotgun proteomic strategy was implemented in order to establish the catalogue of lysine-specific acetylated peptides from four independent $T$. gammatolerans biological cultures. We experienced that $T$. gammatolerans proteome is refractory to classical trypsin proteolysis due to the thermophilic trait of this organism that led to selection of numerous ionic interactions at the surface of proteins to rigidify their structures. For this reason, we applied an in-solution digestion protocol with trypsin including microwave denaturation of proteins prior to proteolysis [30]. A systematic immune-based affinity purification of acetyl-lysine containing peptides from the four samples was performed. As it has been already suggested, recognition of acetylated peptides is more efficient from peptide digest than from a whole protein mixture because the modified residue will not be buried in peptides [31]. Two different antibodies were used for enrichment of acetylated-lysine peptides as specificities between antibodies may be different [32]. Finally, peptides from enriched fractions from four biological replicates were identified by means of nanoLC-MS/MS with a high-resolution mass spectrometer, and lysine acetylation sites were pointed by querying the MS/MS dataset for a 42.01057 Da addition on lysine which is indicative of an acetyl moiety on the $\varepsilon$-amino group of the lysine side chain. High accuracy mass spectrometry with our set-up allows identification of the peptide parent mass with a precision below $5 \mathrm{ppm}$, which is enough to exclude the possibility of a trimethylation of the lysine residue (+ 42.04695 Da). Most of the identifications matched their theoretical mass within 1 ppm highlighting the quality of the dataset obtained with the LTQorbitrap XL mass spectrometer. As our objective was not to compare among different conditions but get a large overview of acetylome, we analyzed hereafter the whole dataset. Among the 66,036 MS/ MS spectra recorded for the four biological samples and the two 
immunopurification protocols, we unambiguously assigned 11,142 MS/ MS spectra leading to the identification of 1324 peptide sequences (Supplementary Tables S1 \& S2). Among these, $2227 \mathrm{MS} / \mathrm{MS}$ spectra correspond to 339 acetylated lysine sites from 181 unique acetylated proteins (Supplementary Tables S3 \& S4). The number of acetylated proteins found in this dataset represents $8.4 \%$ of the $T$. gammatolerans theoretical proteome. This ratio is lower than what was reported for the haloarchaeon $H$. mediterranei $(17.3 \%)$, but higher than for most bacteria (Erwinia amylovora 2.7\%, Thermus thermophilus $5.7 \%$, Geobacillus kaustophilus $3.1 \%$, Bacillus subtilis 4.4\%, and Mycobacterium abscessus 2.3-5.9\%). The percentage of acetylated proteins found in these prokaryotes seems not to be directly in accordance with the complexity of the theoretical proteome since larger genomes often exhibited smallest acetylome extents and may be a consequence of the experimental set up. When comparing the number of acetylated peptides identified from immunoprecipitation experiments performed with either the polyclonal antibodies or the monoclonal antibody, a total of 33 peptides were found common, while 198 and 127 were identified specifically for the polyclonal antibodies or the monoclonal antibody immune-enrichment, respectively. This result confirms that a better coverage of the acetylome can be achieved by increasing the efforts for the sample purification with a broader array of affinity reagents. As previously shown in other prokaryotes, a significant number of $T$. gammatolerans proteins (45\%) contained multiple acetylation sites (Fig. 2). Remarkably, the translation elongation factors EF-1-Alpha (TGAM_1054) and EF-2 (fusA, TGAM_1397), and the phosphoenolpyruvate synthase (TGAM-1043) were found with 10,8 and 7 modifications, respectively. Interestingly, two peptides isolated from TGAM_0191 and TGAM_0460 are acetylated twice. The peptide KPIKVETVLK isolated from TGAM_0460 which is an acetylCoA $C$-acetyltransferase converting two acetyl-CoA molecules into an acetoacetyl-CoA, a substrate for lipid synthesis, was found to be acetylated on the two lysines located at positions +1 and +4 (Supplementary Table S5). These data strongly suggested that several $T$. gammatolerans proteins may be poly-acetylated, at least in exponentially growing phase cells.

In a previous work [21], we have identified a large ratio of the soluble proteome of $T$. gammatolerans validating 951 proteins by nanoLC-MS/MS analysis. We estimated the relative abundance of these proteins by calculating the normalized abundance spectral count factor (NSAF) for each protein. We compared the list of acetylated proteins with these previous data in order to evaluate whether they belong to the most abundant proteins. Among the 181 acetylated proteins found here, 175 were detected in this previous study and most of them $(62 \%)$ were shown to belong to the most abundant proteins (global NASF greater than $0.09 \%$ in the previous study). A limited number of acetylated proteins were found to be among the less abundant entities of the proteome from the standard condition. Among these, a poorly characterized conserved hypothetical protein (TGAM_2047) and the pre-mRNA splicing, snoRNA binding protein (TGAM_0464) represent only $0.0075 \%$ and $0.0045 \%$ of the proteome, respectively.

\subsection{Functional classification of acetylated proteins from T. gammatolerans}

The acetylated proteins were classified into different groups according to their biological process and molecular function established based on annotations, COG categories and KEGG pathways (Supplementary Table S4). As shown in Fig. 3, the "metabolic processes" (45\%) and the "information storage and processing mechanisms" (29\%) are over-represented categories in this dataset.

Central metabolism - T. gammatolerans is able to grow on complex organic compounds or a mixture of 20 amino acids in presence of elemental sulfur $\left(\mathrm{S}^{\circ}\right)$ but also without $\mathrm{S}^{\circ}$ in the presence of sugars as carbon sources [21]. Here, cells were grown in a rich medium containing complex organic compounds and $\mathrm{S}^{\circ}$. Under these experimental conditions, $T$. gammatolerans catabolism is mainly based on peptides and amino-acid degradation and produces $\mathrm{H} 2 \mathrm{~S}$ [21]. As 
shown in Fig. 4, numerous peptidases are found to be acetylated, including two aminopeptidases (TGAM_0800, TGAM_0861), two 20S proteasome beta-subunits (TGAM_1721, TGAM_2052), the pyrolysin (TGAM_1044) and putative amino-, carboxy- or dipeptidases (TGAM_0929, TGAM_0186, and TGAM_0106). The proteinous substrates are assimilated in the subsequent steps, i.e. deamination of the resulting amino-acids into 2 oxo-acids and transformation into the corresponding acids by acetyl- CoA synthetases and succinyl-CoA synthetases (POR, IOR, VOR, ACS, SCS), respectively that produces energy through concomitant ADP phosphorylation. These enzymes also provide the substrates required for other central pathways [33], such as the archaeal modified Embdem- Meyerhof pathway [34], the non-oxidative pentose phosphate pathway [35], as well as for the metabolism of several aminoacids. Interestingly, among the acetylated proteins involved in the modified EmbdenMeyerhof pathway, no enzyme involved in glycolysis (GAPOR, PYK) and only several bidirectional enzymes or the GAPDH enzyme involved in neoglucogenesis pathway are found, suggesting that acetylation could also play a role in the regulation of the flux between glycolysis and neoglucogenesis.

An interesting feature of T. gammatolerans among Thermococcales is the presence of an abundant acetate CoA ligase (TGAM_0230) that may produce ATP and acetate from acetyl$\mathrm{CoA}$ and $\mathrm{CO} 2$ or reversely could transform acetate into acetyl-CoA accompanied by AMP formation [21]. Alternatively, acetyl-CoA molecules may also be used for synthesis of lipids. In archaea, the two first steps are catalyzed by the acetyl-CoA synthetase which transforms two acetyl-CoA molecules into an acetoacetyl-CoA that is subsequently transformed into an HMGCoA by the HMG-CoA synthase. These two enzymes are also found acetylated in the present dataset.

A large variety of hydrogenase complexes exist in $T$. gammatolerans.

The $\mathrm{F}_{420}$ deshydrogenase is supposed to adjust proton concentration into the cells. Like in all other sequenced Thermococcales species, T. gammatolerans encodes orthologues of the membrane-bound Mbh and Mbx complexes [36] that pump protons across the membrane, the resulting proton gradient being used by the ATP synthase to form ATP. Based on our previous semi-quantitative estimation of the amount of proteins in the cells harvested during the exponential phase [21], Mbx components seemed more abundant than Mbh subunits indicating that $\mathrm{Mbx}$ is probably preferentially used in the tested culture condition. One subunit of $\mathrm{F}_{420}$ deshydrogenase, the MbxJ (TGAM_0712) and MbxK (TGAM_0713) subunits, as well as atpH (TGAM_0140), aptE (TGAM_0143) and atpA (TGAM_0146), and three subunits of the ATP synthase are found to be acetylated.

Transcription and translation - Among the proteins involved in transcription, the RNA polymerase subunit (rpoB), the initiation factor TBP, the Tbp interacting protein (TGAM_0640), six putative transcriptional regulators, and several other proteins were found acetylated (Supplementary Table S4). The homolog of rpoB subunit in E. coli has been already described as being acetylated [37], showing the conservation of this mechanism among prokaryotes. Regarding translation, among the 64 ribosomal proteins, 9 belonging to the large ribosome and one to the small ribosome subunits were found acetylated, as well as several initiation and elongation factors, and 14 out of the 20 aminoacyl tRNA synthetases. The Elongation factor 1-alpha (TGAM_1054) and the translation elongation factor EF-2 (TGAM_1397) are the two proteins which exhibited the highest number of acetylation sites: 10 and 8, respectively. An important number of proteins involved in translation were found acetylated both in bacteria and in the archaeon $H$. mediterranei [18]. It has been proposed that polyacetylation could participate in regulation of ribosome function and protein biosynthesis.

\subsection{Conservation of acetylated sites between two distantly related Euryarchaeota}


The specific patterns of amino acid residues surrounding the lysine acetylation sites observed with the two different antibodies exhibit some differences (Supplemental Data 1). More importantly, we compared the position of lysine acetylation in orthologous proteins from the two archaeal species for which we have now comprehensive experimental data (Supplementary Fig. S1, Supplementary Table S6). From this set of proteins, 99 acetylated proteins from $H$. mediterranei have an ortholog in $T$. gammatolerans, whereas $46 \mathrm{~T}$. gammatolerans acetylated proteins have an ortholog in $H$. mediterranei and only 26 orthologous proteins were found to be acetylated in both species (Supplementary Table S7). These proteins are mainly involved in translation and in different metabolic pathways. They may comprise several acetylation sites that could be conserved or not in their respective orthologs. We checked whether a lysine acetylated site in one protein at a given position was also found acetylated in the orthologous protein at the same position. From a total of 199 common lysine positions in the 26 pairs of orthologous proteins, 67 in T. gammatolerans and 58 in $H$. mediterranei are acetylated, but only three of them are acetylated at the same position in both orthologs (Supplementary Table S8, Supplementary Fig. S1). Interestingly, while the translation elongation factor EF-1-Alpha (TGAM_1054) contains 10 acetylation sites and the H. mediterranei ortholog (HFX_0346) encompasses six sites, only one site is found to be acetylated in both species among the 13 putative sites conserved in both proteins. Since this protein sequence is very well conserved in these archaea $\left(\mathrm{E}=3.0 \mathrm{E}^{-137}\right.$ and $8.0 \mathrm{E}^{-144}$, with a max bitscore >0.6), these results suggest that in archaea $N^{\varepsilon}$-Lysine acetylation is either conserved for a given protein but not at the same sites, or a highly dynamic mechanism occurs which is not comprehensively detected by the current shotgun procedure.

\subsection{Nucleoid structure and dynamics}

It was previously shown that mutation on the acetylated site of one of the 13 Cdc6A encoded by $H$. mediterranei destroyed the ARS activity of its adjacent origin oriC1 [18]. $T$. gammatolerans only encodes one Cdc6 (TGAM_0128) that was not found to be acetylated in our studies. In contrast, we report herein, among the acetylated proteins, several proteins described as involved in cell division and replication: the FtsZ-like protein (TGAM_1841), a cell division GTPase, a parB-like nuclease (TGAM_1907), the RPA41 subunit of replication factor A complex (TGAM_1760), a PP-loop ATPase, mrp-like protein (TGAM_0229), a recJlike single-stranded exonuclease (TGAM_1460), the Gins 23 protein (TGAM_2023), as well as a primase-related protein (TGAM_1776). The reverse gyrase, a topoisomerase I that introduces positive supercoiling into DNA, is only encoded by hyperthermophilic organisms [38]. This protein was also found to be acetylated on two adjacent sites (Lys79 and Lys80). These lysines are conserved in the protein encoded by Thermotoga maritima which has been crystalized (PDB ID: 4ddu). They are located in the RecA-like H1 domain of the protein [39]. T. gammatolerans is able to resist to massive doses of ionizing radiations, but only a few DNA repair proteins, a Rad55-like protein (TGAM_0280) and a putative AP endonuclease (TGAM_1637), were found acetylated. However, we cannot exclude that acetylation on DNA repair proteins occurs when cells are exposed to DNA damaging agents. Altogether, these results showed that acetylation may be an important partner for essential mechanisms of DNA integrity maintenance in $T$. gammatolerans.

Interestingly, we found that the histone A2 (also named histone B, TGAM_0477), composed of 67 amino acids, is acetylated in T. gammatolerans at least at two different sites (Supplementary Table S3): $\mathrm{K}_{27}$ and $\mathrm{K}_{36}$, (numbering assuming that the $\mathrm{N}$-terminal positions methionine is not processed). Another peptide common to histones A and B and located in the C-terminus was found acetylated at $\mathrm{K}_{62}$. Fig. 5 shows the MS/MS spectra of two histone acetylated peptides. In panel A, the MS/MS spectrum $(\mathrm{m} / \mathrm{z}$ at 867.98627 , doubly charged ion, $\Delta$ mass $1 \mathrm{ppm}$ ) corresponds to the [28-42] tryptic peptide of Histone B that is acetylated. In this 
case, the peptide fragments obtained after collisional-induced dissociation clearly indicate acetylation on Lys36. The $\mathrm{y}_{7}{ }^{+}$fragment $(\mathrm{m} / z$ at 814.5033$)$ and $\mathrm{b}_{9}{ }^{2+}$ fragment $(\mathrm{m} / z$ at 546.2902$)$ as well as $\mathrm{y}_{8}{ }^{+}$fragment $(\mathrm{m} / \mathrm{z}$ at 943.5459$)$ and $\mathrm{b}_{10}{ }^{2+}$ fragment $(\mathrm{m} / \mathrm{z}$ at 581.8088$)$ are the most informative ions. In panel B, the MS/MS spectrum $(\mathrm{m} / \mathrm{z}$ at 535.8137 , doubly charged ion, $\Delta$ mass $-0.3 \mathrm{ppm}$ ) corresponds to the [258-66] tryptic acetylated peptide common to histones A and B. In this case, the peptide fragments obtained after collisional-induced dissociation clearly indicate acetylation on Lys62. The $\mathrm{y}_{5}{ }^{+}$fragment $(\mathrm{m} / \mathrm{z}$ at 642.4297$)$ and $\mathrm{b}_{5}{ }^{+}$fragment $(\mathrm{m} / \mathrm{z}$ at 546.2902) are the most informative ions. Archaeal histones are homologous to their $\mathrm{H} 3-\mathrm{H} 4$ eukaryotic counterparts and are well conserved among Euryarchaeota, but are not reputed to be post-translationally modified since archaeal histones lack the N-terminal domain of eukaryotic histones, on which most of the PTMs occur in eukaryotes [40]. Alba, which plays an important role for chromatin structure of Sulfolobales that do not encode histones, is also post translationally modified but is methylated on $\mathrm{K}_{16}$ [36].

The chromatin structure of $T$. kodakaraensis, a phylogenetically closely-related species has been investigated, highlighting a classical beads-of-the-string structure mainly formed by DNA and histones and also a thick fibrous structure composed of DNA, histones, Alba and TrmBL2 proteins [25]. In order to check whether acetylation also occurs in histones from $T$. kodakaraensis, we extracted its chromatin from mid-log phase cells as well as from late stationary cells, and directly analyzed the presence of acetylated peptides from the proteins with a molecular weight of $15 \mathrm{kDa}$. As shown in Fig. 6 the histone A and B sequences from $T$. kodakaraensis and T. gammatolerans are well conserved. Six lysine positions are perfectly conserved among the four sequences while three other lysine positions are not conserved. The analysis of acetylated peptides in T. kodakaraensis species shows that both histones A and B can be acetylated on several acetylation sites. We identified up to six acetylated sites in the histone B of T. kodakaraensis (Fig. 6, Supplementary Table S9). Histone A from $T$. kodakaraensis displays three acetylated sites, two of them being common to histone B. The same peptides were also found unacetylated in the tryptic digestion of chromatin-enriched 15 $\mathrm{kDa}$ proteins, supporting the idea that all the histones extracted from the chromatin are not acetylated at each site. The number of acetylated peptides increased when chromatin was extracted from late stationary phase cells (Supplementary Table S9). Altogether these results suggest this post-translational modification on histones is a dynamic mechanism in Thermococcales species.

Recently, the structure of a $90 \mathrm{pb}$ DNA fragment bound to three homodimers of histone B (HMfB) from the archaeon Methanothermus fervidus has been published [41]. Interaction modes with DNA are very similar between the archaeal and eukaryotic structures as well the dimer:dimer arrangements while the surface of the archaeal histone complex/dimer displays a less positive charge [41]. Nevertheless, the HMfB dimers are symmetric and polymerize to form with the wrapped DNA an endless left-handed rod which Henneman et al proposed to call "hypernucleosome" [42].

The 3D structures of the histones from T. gammatolerans or T. kodakaraensis have not been characterized experimentally. T. kodakaraensis histone homodimers TkHA/TkHA, TkHB/TkHB and heterodimer TkHA/TkHB structural models were built using as template the $\mathrm{X}$-ray structure of $P$. horikoshii, (PDB code; 1ku5), a Thermococcale species (Supplementary Fig. S2). The 3D structures of the dimer models (TkHA/TkHA, TkHB/TkHB and TkHA/TkHB from T. kodakaraensis) are very similar to the histone B dimer MfHB from Methanothermus fervidus (all RMSD values $\sim 0.73 \AA$ ). Using the X-ray structure of the polymer of $M$. fervidus (PDB code: 5t5k), we built models of hexamers from three pairs of histones TkHA/TkHA, TkHB/TkHB and TkHA/TkHB. All models display a very good overlay with the X-ray structure of M. fervidus as shown in Supplementary Fig. S3 which represents the structure alignment of three consecutive TkHB dimers with three dimers of MfHB. One should notice 
that the resolution of the X-ray structure of the polymer of HMfB is $4 \AA$, thus, the position of side-chains in the X-ray structure remains imprecise. However, it was proposed that interactions of four residue pairs (E30-K61, E34-K65, K14-Q48, K26-E58, positions based on the sequences starting with the second amino acid residue), are involved in hypernucleosome stability and compactness [42]. Interestingly three out of the four lysines (K26, K61, K65) are found to be acetylated (Supplementary Table S9). In this model, acetylation could affect lysine interaction with acidic residues (E30, E54 and E58 residues, respectively). It could destabilize dimer:dimer stacking and thus the compactness of two adjacent histone layers (Fig. 7). All these acetylation sites are conserved between HtkA and $\mathrm{HTkB}$, as well as the three glutamates (E31, E35 and E59 residues), suggesting that the impact of these lysine acetylations is the same in the three dimer forms (e.g. HTkA/ HTkA, HTkB/HTkB and HTkA/HTkB). Strikingly, K42 is in proximity to the carboxyl-terminus of both the other monomer and of the adjacent dimer $(\mathrm{N}+$ 1) (Supplementary Fig. S4). We can hypothesize that its acetylation could also affect the stability of the dimer and/or the polymerization process. In addition, we also propose that the K57 residue interact with DNA (Supplementary Fig. S5) and suggest that acetylation might reduce the affinity for DNA. It was already reported that lysine acetylation of HU, a histonelike protein, alters its DNA binding properties and may modulate the chromosome organization of Mycobacterium tuberculosis [43]. The impact of K35 acetylation is unclear as this lysine is not conserved and is replaced by a tyrosine in histone B (Fig. 6). Finally, the N-terminus of $\mathrm{HTkB}$ has also been found acetylated on an alanine residue. We already reported that several cytosolic and membrane proteins from $T$. gammatolerans were acetylated at their N-terminal residue after excision of the N-terminal methionine [21]. From the N-terminal peptidic signatures that were recorded, we deduced that $T$. gammatolerans encodes a functional analogue of NatA because several acetylation occurred on an alanine located at position 2 [21]. It has been shown that, $\mathrm{H} 2 \mathrm{~A}$ and $\mathrm{H} 4$ histones exhibited acetylated serine residues located at the $\mathrm{N}$-terminal of these proteins in S. cerevisiae and maintenance of $\mathrm{N}$-terminal acetylation of histone $\mathrm{H} 4$ reduced the extension of lifespan mediated by calorie restriction [44,45].

Altogether, the acetylome data along with the structural models of histone polymers of $T$. kodakarensis strongly suggest that lysine acetylation in histone A and B may play an important role in histone assembly and/or interaction with DNA. The regulation of gene expression in eukaryotic species is mainly driven by post-translational modifications of histone tails that are lacking in most of the archaeal ones. We can hypothesize that the acetylation of lysines involved in dimer:dimer or histone:DNA interactions could ensure the regulation of gene expression by disrupting interaction with DNA or hypernucleosome assembly, thus destabilizing the chromatin structure. Mattiroli et al [41] showed that perturbation of hypernucleosome function in vivo driven by a mutation on G17 in T. kodakarensis modifies the response to nutrient change, suggesting a role in transcription. These results could also explain why histone acetylated peptides were mostly found in an enriched-chromatin protein extracts from stationary phase cells. Finally, we also found that not only histones but also TrmBL2 and Alba from proteins are acetylated in these Thermococcus species. TrmBL2 (TGAM_1678) from T. gammatolerans was found to be acetylated on K192 and K198, and Alba from T. kodakaraensis is acetylated on the N-terminal of the protein. This acetylation has already also been recently reported for Alba from Sulfolobus islandicus [15]. The lack of structure of TrmBL2 prevents the ability to model the impact of acetylation on TrmBL2 activity but all these results suggested that acetylation of other chromatin proteins may also modulate the dynamics of the genome structure.

\section{Conclusions}


The aim of the present study was to verify whether lysine-specific acetylation of proteins occurs at a genome-wide scale in the archaeon Thermococcus gammatolerans. We established an in-depth acetylome panorama for $T$. gammatolerans. A total of $316 \mathrm{~N} \varepsilon$-Lysine peptides were confidently identified, with 338 distinct acetylation sites listed from 181 unique protein sequences. We compared the acetylome patterns of $T$. gammatolerans and $H$. mediterranei archaea which belong to the same Euryarchaeota lineage and evidenced strong differences that call for further experimental comparative studies. We evidenced for the first time that histones from two different archaea, namely $T$. gammatolerans and $T$. kodakaraensis, can be acetylated at various positions. This discovery reinforces the strong evolutionary link between Archaea and Eukaryotes and pleads for further investigation on the extent and role of acetylation of histones in Archaea.

\section{Conflict of interest}

The authors do not have any conflict of interest to declare.

\section{CRediT authorship contribution statement}

Béatrice Alpha-Bazin: Conceptualization, Investigation, Validation, Data curation, Writing - original draft.

Aurore Gorlas: Investigation, Resources.

Arnaud Lagorce: Investigation, Resources.

Damien Joulié: Investigation.

Jean-Baptiste Boyer: Investigation.

Murielle Dutertre:Investigation, Resources.

Jean-Charles Gaillard: Investigation.

Anne Lopes: Methodology, Formal analysis.

Yvan Zivanovic: Methodology, Formal analysis.

Alain Dedieu: Conceptualization, Validation, Supervision.

Fabrice Confalonieri: Conceptualization, Investigation, Validation, Formal analysis, Supervision, Writing - original draft, Project administration, Funding acquisition.

Jean Armengaud: Conceptualization, Validation, Formal analysis, Supervision, Writing original draft, Project administration, Funding acquisition.

\section{Data availability}

The data are deposited in the PRIDE repository

\section{Acknowledgements}

We thank the Agence Nationale de la Recherche ("GAMMATOLERANS" project, ANR12-BSV6-0012) for financial support. 


\section{References}

[1] V.G. Allfrey, R. Faulkner, A.E. Mirsky, Acetylation and methylation of histones and their possible role in the regulation of Rna synthesis, Proc. Natl. Acad. Sci. U. S. A. 51 (1964) 786-794.

[2] D.M. Phillips, The presence of acetyl groups of histones, Bochem J 87 (1963) 258263.

[3] A. Drazic, L.M. Myklebust, R. Ree, T. Arnesen, The world of protein acetylation, Biochim. Biophys. Acta 1864 (10) (2016) 1372-1401.

[4] J. Soppa, Protein acetylation in archaea, bacteria, and eukaryotes, Archaea 2010 (2010).

[5] V.J. Carabetta, I.M. Cristea, Regulation, Function, and Detection of protein acetylation in Bacteria, J. Bacteriol. 199(16) (2017).

[6] S. Bonissone, N. Gupta, M. Romine, R.A. Bradshaw, P.A. Pevzner, N-terminal protein processing: a comparative proteogenomic analysis, Mol. Cell. Proteomics 12 (1) (2013) $14-28$.

[7] E.A. Vorontsov, E. Rensen, D. Prangishvili, M. Krupovic, J. Chamot-Rooke, Abundant lysine methylation and N-terminal acetylation in Sulfolobus islandicus revealed by bottom-up and top-down proteomics, Mol. Cell. Proteomics 15 (11) (2016) 3388-3404.

[8] D.G. Christensen, J.T. Baumgartner, X. Xie, K.M. Jew, N. Basisty, B. Schilling, M. L. Kuhn, A.J. Wolfe, Mechanisms, detection, and relevance of protein acetylation in prokaryotes, mBio 10 (2) (2019).

[9] B. Macek, K. Forchhammer, J. Hardouin, E. Weber-Ban, C. Grangeasse, I. Mijakovic, Protein post-translational modifications in bacteria, Nat Rev Microbiol 17 (11) (2019) 651-664.

[10] V. Bernal, S. Castano-Cerezo, J. Gallego-Jara, A. Ecija-Conesa, T. de Diego, J. L. Iborra, M. Canovas, Regulation of bacterial physiology by lysine acetylation of proteins, New Biotechnol. 31 (6) (2014) 586-595.

[11] J. Ren, Y. Sang, J. Lu, Y.F. Yao, Protein acetylation and its role in bacterial virulence, Trends Microbiol. 25 (9) (2017) 768-779.

[12] C.M. VanDrisse, J.C. Escalante-Semerena, Protein acetylation in Bacteria, Annu. Rev. Microbiol. 73 (2019) 111-132.

[13] T. Hase, S. Wakabayashi, H. Matsubara, L. Kerscher, D. Oesterhelt, K.K. Rao, D. O. Hall, Complete amino acid sequence of Halobacterium halobium ferredoxin containing an Nepsilon-acetyllysine residue, J. Biochem. 83 (6) (1978) 1657-1670.

[14] S.D. Bell, C.H. Botting, B.N. Wardleworth, S.P. Jackson, M.F. White, The interaction of Alba, a conserved archaeal chromatin protein, with Sir2 and its regulation by acetylation, Science 296 (5565) (2002) 148-151.

[15] J. Cao, Q. Wang, T. Liu, N. Peng, L. Huang, Insights into the post-translational modifications of archaeal Sis10b (Alba): lysine-16 is methylated, not acetylated, and this does not regulate transcription or growth, Mol. Microbiol. 109 (2) (2018) 192-208.

[16] M. Aivaliotis, K. Gevaert, M. Falb, A. Tebbe, K. Konstantinidis, B. Bisle, C. Klein, L. Martens, A. Staes, E. Timmerman, J. Van Damme, F. Siedler, F. Pfeiffer, J. Vandekerckhove, D. Oesterhelt, Large-scale identification of N-terminal peptides in the halophilic archaea Halobacterium salinarum and Natronomonas pharaonis, J. Proteome Res. 6 (6) (2007) 21952204.

[17] P.A. Kirkland, M.A. Humbard, C.J. Daniels, J.A. Maupin-Furlow, Shotgun proteomics of the haloarchaeon Haloferax volcanii, J. Proteome Res. 7 (11) (2008) 5033-5039.

[18] J. Liu, Q. Wang, X. Jiang, H. Yang, D. Zhao, J. Han, Y. Luo, H. Xiang, Systematic analysis of lysine acetylation in the Halophilic Archaeon Haloferax mediterranei, J. Proteome Res. 16 (9) (2017) 3229-3241. 
[19] E. Jolivet, S. L'Haridon, E. Corre, P. Forterre, D. Prieur, Thermococcus gammatolerans sp. nov., a hyperthermophilic archaeon from a deep-sea hydrothermal vent that resists ionizing radiation, Int. J. Syst. Evol. Microbiol. 53 (Pt 3) (2003) 847-51.

[20] A. Tapias, C. Leplat, F. Confalonieri, Recovery of ionizing-radiation damage after high doses of gamma ray in the hyperthermophilic archaeon Thermococcus gammatolerans, Extremophiles 13 (2) (2009) 333-343.

[21] Y. Zivanovic, J. Armengaud, A. Lagorce, C. Leplat, P. Guerin, M. Dutertre, V. Anthouard, P. Forterre, P. Wincker, F. Confalonieri, Genome analysis and genome-wide proteomics of Thermococcus gammatolerans, the most radioresistant organism known amongst the Archaea, Genome Biol. 10 (6) (2009) R70.

[22] A. de Groot, R. Dulermo, P. Ortet, L. Blanchard, P. Guerin, B. Fernandez, B. Vacherie, C. Dossat, E. Jolivet, P. Siguier, M. Chandler, M. Barakat, A. Dedieu, V. Barbe, T. Heulin, S. Sommer, W. Achouak, J. Armengaud, Alliance of proteomics and genomics to unravel the specificities of Sahara bacterium Deinococcus deserti, PLoS Genet. 5 (3) (2009), e1000434.

[23] G. Clair, J. Armengaud, C. Duport, Restricting fermentative potential by proteome remodeling: an adaptive strategy evidenced in Bacillus cereus, Mol. Cell. Proteomics 11 (6) (2012) M111-013102.

[24] G. Klein, C. Mathe, M. Biola-Clier, S. Devineau, E. Drouineau, E. Hatem, L. Marichal, B. Alonso, J.C. Gaillard, G. Lagniel, J. Armengaud, M. Carriere, S. Chedin, Y. Boulard, S. Pin, J.P. Renault, J.C. Aude, J. Labarre, RNA-binding proteins are a major target of silica nanoparticles in cell extracts, Nanotoxicology 10 (10) (2016) 1555-1564.

[25] H. Maruyama, M. Shin, T. Oda, R. Matsumi, R.L. Ohniwa, T. Itoh, K. Shirahige, T. Imanaka, H. Atomi, S.H. Yoshimura, K. Takeyasu, Histone and TK0471/TrmBL2 form a novel heterogeneous genome architecture in the hyperthermophilic archaeon Thermococcus kodakarensis, Mol. Biol. Cell 22 (3) (2011) 386-398.

[26] E.M. Hartmann, F. Allain, J.C. Gaillard, O. Pible, J. Armengaud, Taking the shortcut for high-throughput shotgun proteomic analysis of bacteria, Methods Mol. Biol. 1197 (2014) $275-285$.

[27] F. Corpet, Multiple sequence alignment with hierarchical clustering, Nucleic Acids Res. 16 (22) (1988) 10881-10890.

[28] M. Biasini, S. Bienert, A. Waterhouse, K. Arnold, G. Studer, T. Schmidt, F. Kiefer, T. Gallo Cassarino, M. Bertoni, L. Bordoli, T. Schwede, SWISS-MODEL: modelling protein tertiary and quaternary structure using evolutionary information, Nucleic Acids Res. 42 (Web Server issue) (2014) W252-W258.

[29] E.W. Deutsch, N. Bandeira, V. Sharma, Y. Perez-Riverol, J.J. Carver, D.J. Kundu, D. Garcia-Seisdedos, A.F. Jarnuczak, S. Hewapathirana, B.S. Pullman, J. Wertz, Z. Sun, S. Kawano, S. Okuda, Y. Watanabe, H. Hermjakob, B. MacLean, M. J. MacCoss, Y. Zhu, Y. Ishihama, J.A. Vizcaino, The ProteomeXchange consortium in 2020: enabling 'big data' approaches in proteomics, Nucleic Acids Res. 48 (D1) (2020) D1145-D1152.

[30] Y.S. Yang, B. Fernandez, A. Lagorce, V. Aloin, K.M. De Guillen, J.B. Boyer, A. Dedieu, F. Confalonieri, J. Armengaud, C. Roumestand, Prioritizing targets for structural biology through the lens of proteomics: the archaeal protein TGAM_1934 from Thermococcus gammatolerans, Proteomics 15 (1) (2015) 114-123.

[31] K.L. Guan, W. Yu, Y. Lin, Y. Xiong, S. Zhao, Generation of acetyllysine antibodies and affinity enrichment of acetylated peptides, Nat. Protoc. 5 (9) (2010) 1583-1595.

[32] P.G. Shaw, R. Chaerkady, Z. Zhang, N.E. Davidson, A. Pandey, Monoclonal antibody cocktail as an enrichment tool for acetylome analysis, Anal. Chem. 83 (10) (2011) $3623-3626$. 
[33] C. Brasen, D. Esser, B. Rauch, B. Siebers, Carbohydrate metabolism in Archaea: current insights into unusual enzymes and pathways and their regulation, Microbiol. Mol. Biol. Rev. 78 (1) (2014) 89-175.

[34] T. Sato, H. Atomi, Novel metabolic pathways in Archaea, Curr. Opin. Microbiol. 14 (3) (2011) 307-314.

[35] I. Orita, T. Sato, H. Yurimoto, N. Kato, H. Atomi, T. Imanaka, Y. Sakai, The ribulose monophosphate pathway substitutes for the missing pentose phosphate pathway in the archaeon Thermococcus kodakaraensis, J. Bacteriol. 188 (13) (2006) 4698-4704.

[36] G.J. Schut, E.S. Boyd, J.W. Peters, M.W. Adams, The modular respiratory complexes involved in hydrogen and sulfur metabolism by heterotrophic hyperthermophilic archaea and their evolutionary implications, FEMS Microbiol. Rev. 37 (2) (2013) 182-203.

[37] B.P. Lima, H. Antelmann, K. Gronau, B.K. Chi, D. Becher, S.R. Brinsmade, A. J. Wolfe, Involvement of protein acetylation in glucose-induced transcription of a stressresponsive promoter, Mol. Microbiol. 81 (5) (2011) 1190-1204.

[38] C. Brochier-Armanet, P. Forterre, Widespread distribution of archaeal reverse gyrase in thermophilic bacteria suggests a complex history of vertical inheritance and lateral gene transfers, Archaea 2 (2) (2007) 83-93.

[39] M.G. Rudolph, Y. del Toro Duany, S.P. Jungblut, A. Ganguly, D. Klostermeier, Crystal structures of Thermotoga maritima reverse gyrase: inferences for the mechanism of positive DNA supercoiling, Nucleic Acids Res. 41 (2) (2013) 1058-1070.

[40] K. Luger, T.J. Richmond, The histone tails of the nucleosome, Curr. Opin. Genet. Dev. 8 (2) (1998) 140-146.

[41] F. Mattiroli, S. Bhattacharyya, P.N. Dyer, A.E. White, K. Sandman, B.W. Burkhart, K.R. Byrne, T. Lee, N.G. Ahn, T.J. Santangelo, J.N. Reeve, K. Luger, Structure of histonebased chromatin in Archaea, Science 357 (6351) (2017) 609-612.

[42] B. Henneman, C. van Emmerik, H. van Ingen, R.T. Dame, Structure and function of archaeal histones, PLoS Genet. 14 (9) (2018), e1007582.

[43] S. Ghosh, B. Padmanabhan, C. Anand, V. Nagaraja, Lysine acetylation of the Mycobacterium tuberculosis HU protein modulates its DNA binding and genome organization, Mol. Microbiol. 100 (4) (2016) 577-588.

[44] D. Molina-Serrano, V. Schiza, C. Demosthenous, E. Stavrou, J. Oppelt, D. Kyriakou, W. Liu, G. Zisser, H. Bergler, W. Dang, A. Kirmizis, Loss of Nat4 and its associated histone $\mathrm{H} 4 \mathrm{~N}$-terminal acetylation mediates calorie restriction-induced longevity, EMBO Rep. 17 (12) (2016) 1829-1843.

[45] O.K. Song, X. Wang, J.H. Waterborg, R. Sternglanz, An Nalpha-acetyltransferase responsible for acetylation of the N-terminal residues of histones $\mathrm{H} 4$ and H2A, J. Biol. Chem. 278 (40) (2003) 38109-38112. 


\section{Figure1}

Detection of lysine-acetylated proteins. Western blotting analysis using either antiacetylated-lysine rabbit polyclonal antibody (PAB) with $20 \mu \mathrm{g}$ (Lane 1), $10 \mu \mathrm{g}$ (Lane 2) of extracted proteins of $T$. gammatolerans and $15 \mu \mathrm{g}$ (Lane 3) of extracted proteins of Saccharomyces cerevisiae, or anti-acetylated-lysine rabbit monoclonal antibody (MAB) with $20 \mu \mathrm{g}$ (Lane 4), $10 \mu \mathrm{g}$ (Lane 5) of extracted proteins of T. gammatolerans and $15 \mu \mathrm{g}$ (Lane 6) of extracted proteins of $S$. cerevisiae. The molecular weights of the protein markers are indicated in $\mathrm{kDa}$ (Lane M).

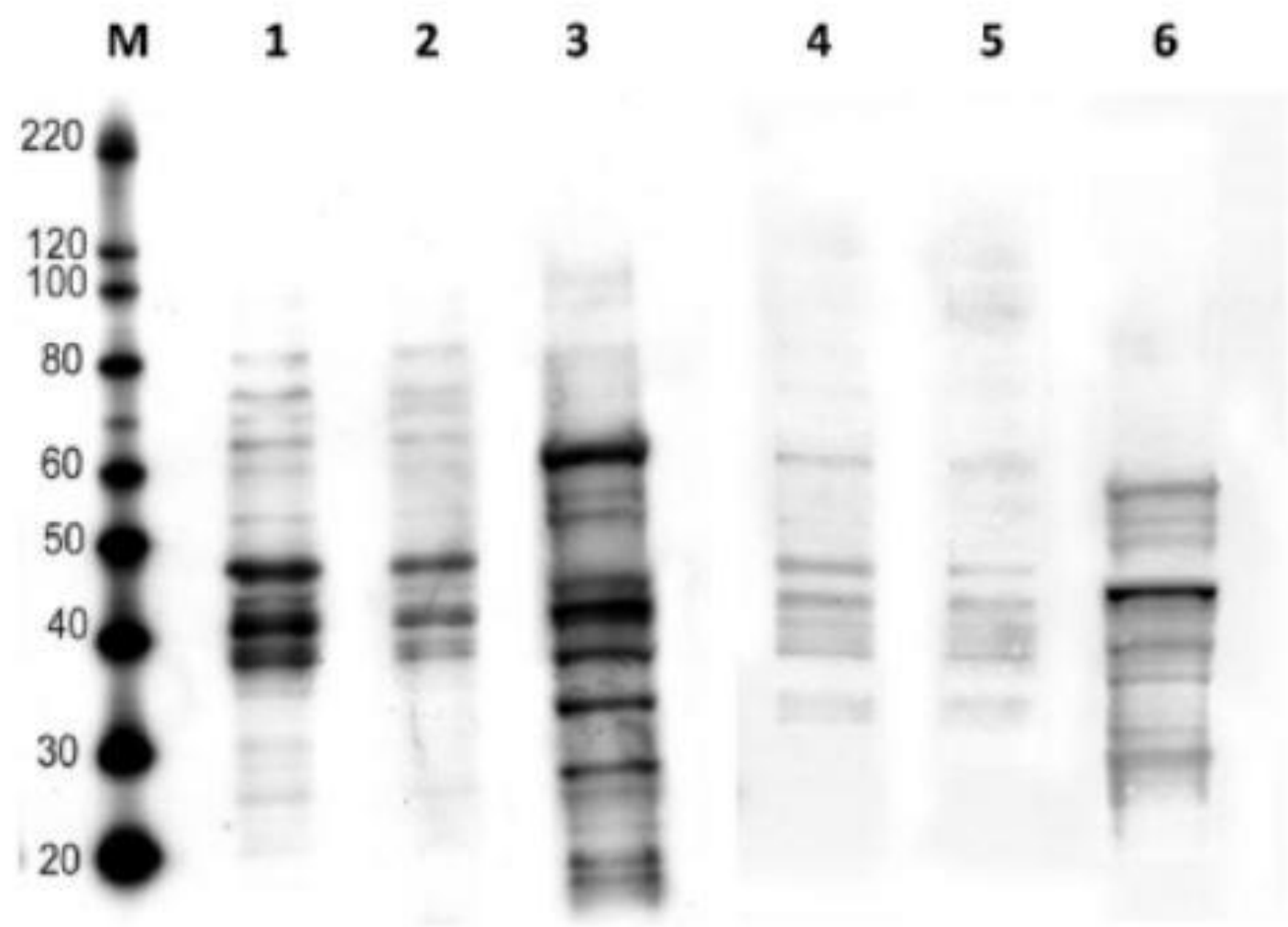




\section{Figure 2}

Distribution of $T$. gammatolerans proteins along the number of acetylated sites. The proteins with 7, 8 and 10 acetylated sites are the PEP synthase, EF-2, and EF-1-alpha, respectively.

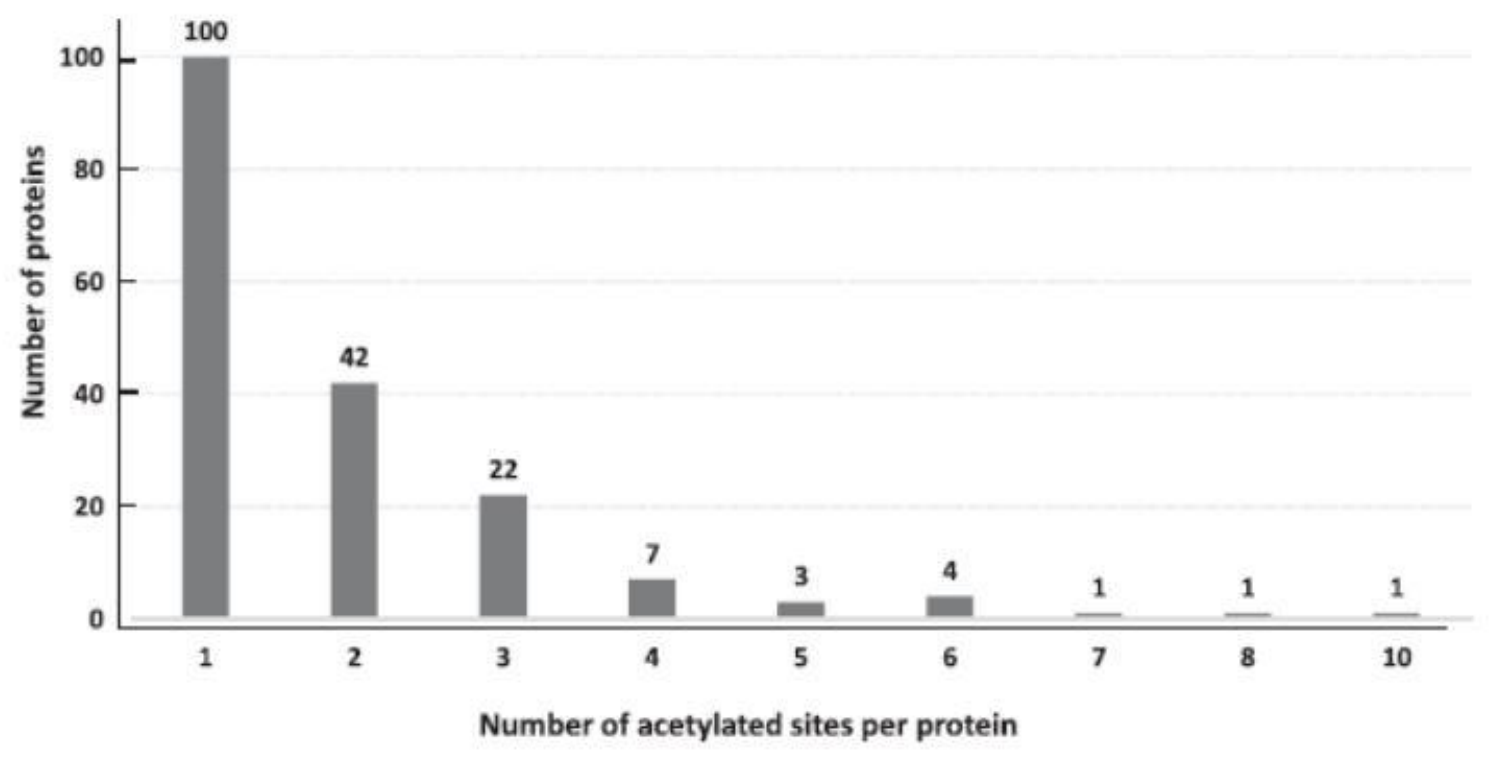




\section{Figure 3}

Functional classification of $T$. gammatolerans acetylated proteins based on COG classification and KEGG pathways. Detailed categories are presented for the three main groups: "metabolism" (blue), "information, storage and processing" (green), and "cellular processes and signaling" (red). (For interpretation of the references to colour in this fig. legend, the reader is referred to the web version of this article).

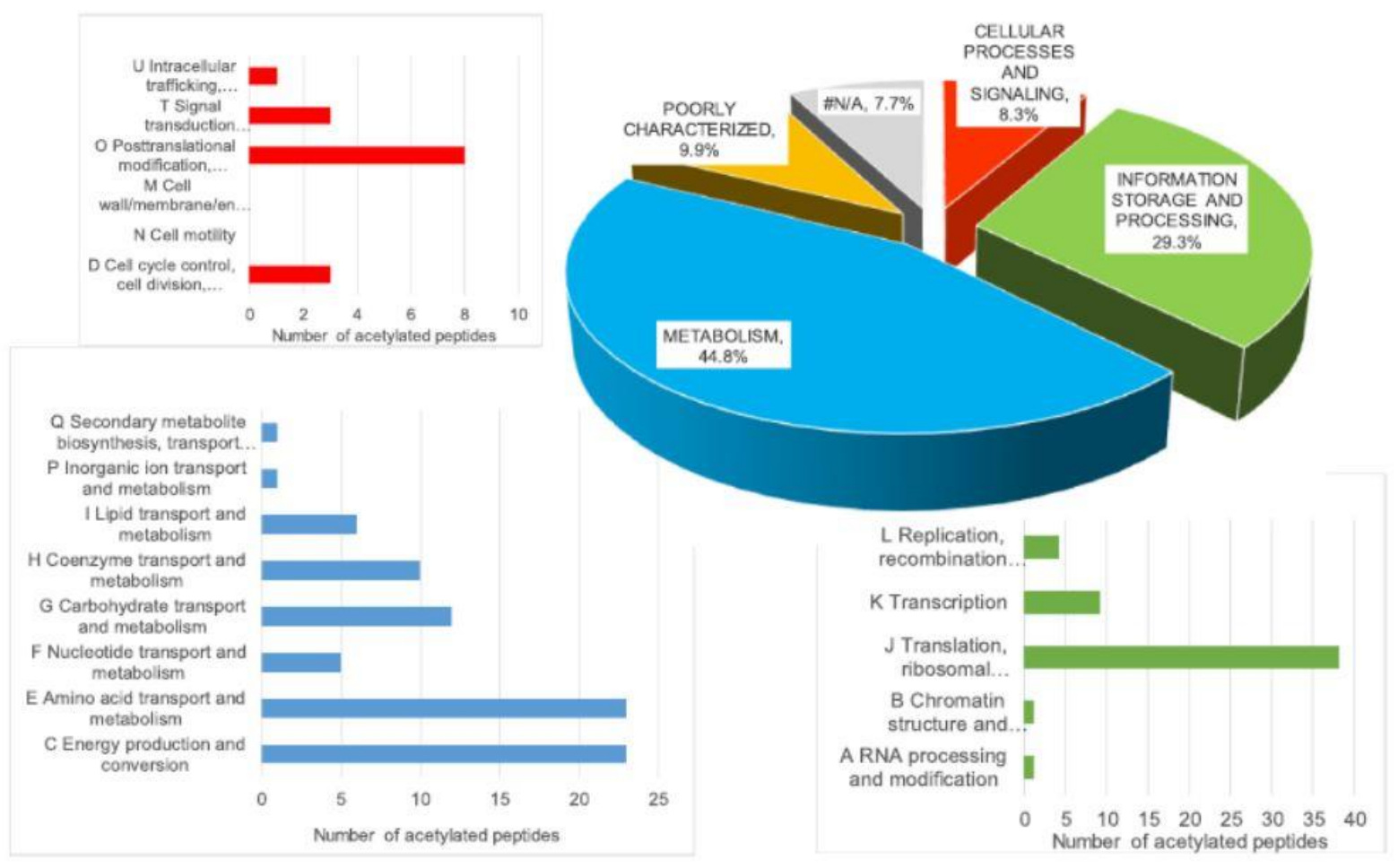




\section{Figure 4}

Role of acetylated enzymes in T. gammatolerans central metabolic pathways. Acetylated proteins are indicated in red and circled in red. Fig. adapted from [42] showing the main metabolic pathways: Peptide and amino acid degradation, Pseudo TCA cycle, Modified Embden Meyerhof glycolytic pathway, Non oxidative pentose pathway, Pyruvate degradation and Lipid synthesis. (For interpretation of the references to colour in this fig. legend, the reader is referred to the web version of this article.)

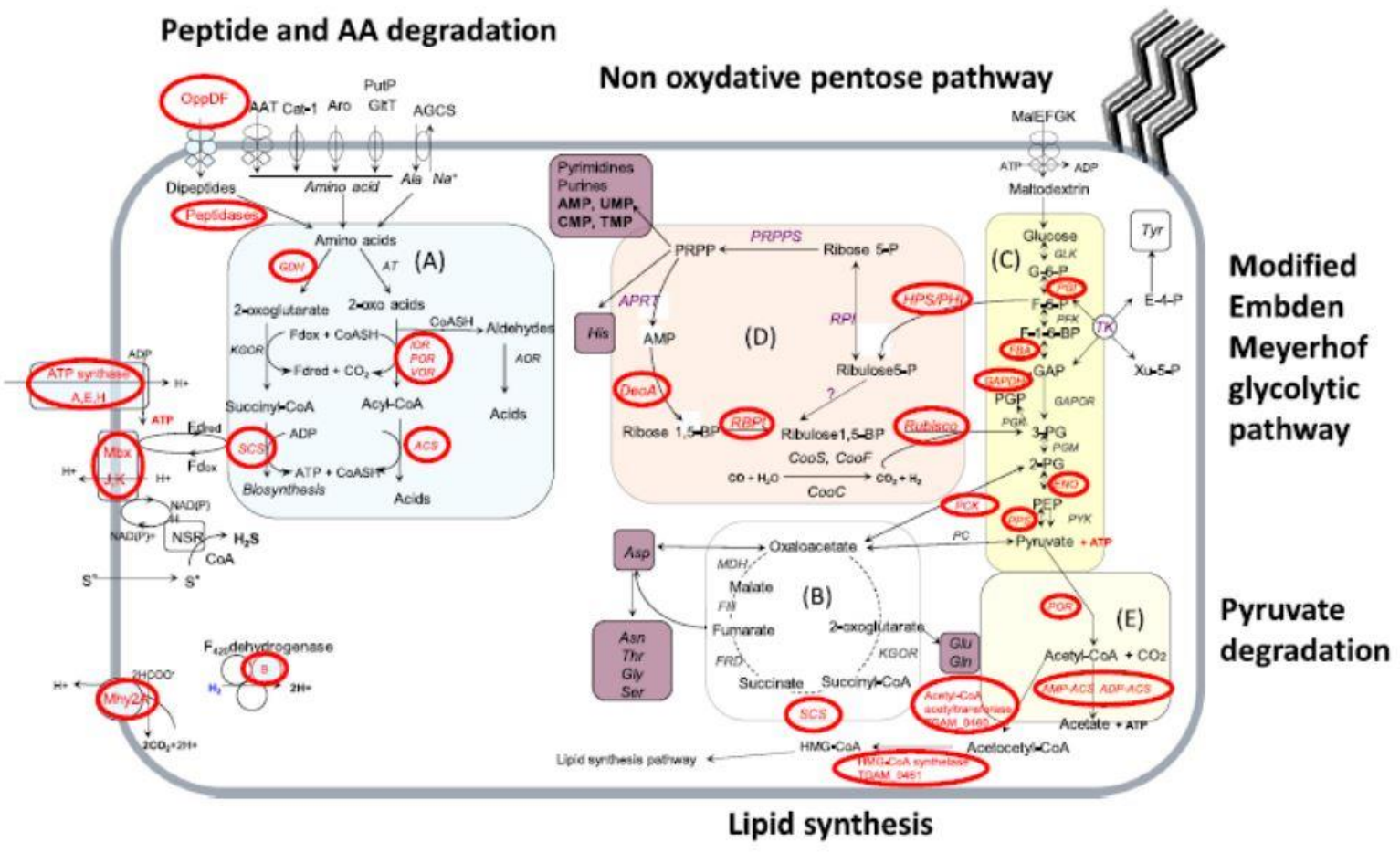




\section{Figure 5}

Examples of acetylation site identification in histones by tandem mass spectrometry. A. MS/MS spectrum of the acetylated [VLAEHLEEKacAIEIAK] tryptic peptide from $T$. gammatolerans Histone B (TGAM_0477). B. MS/MS spectrum of the acetylated [AEDIKacLAIR] peptide which is common in T. gammatolerans histone A or B protein sequences. In both spectra $\mathrm{N}$-terminal fragment ions (b-type ions) and C-terminal fragment ions (y-type ions) are indicated.

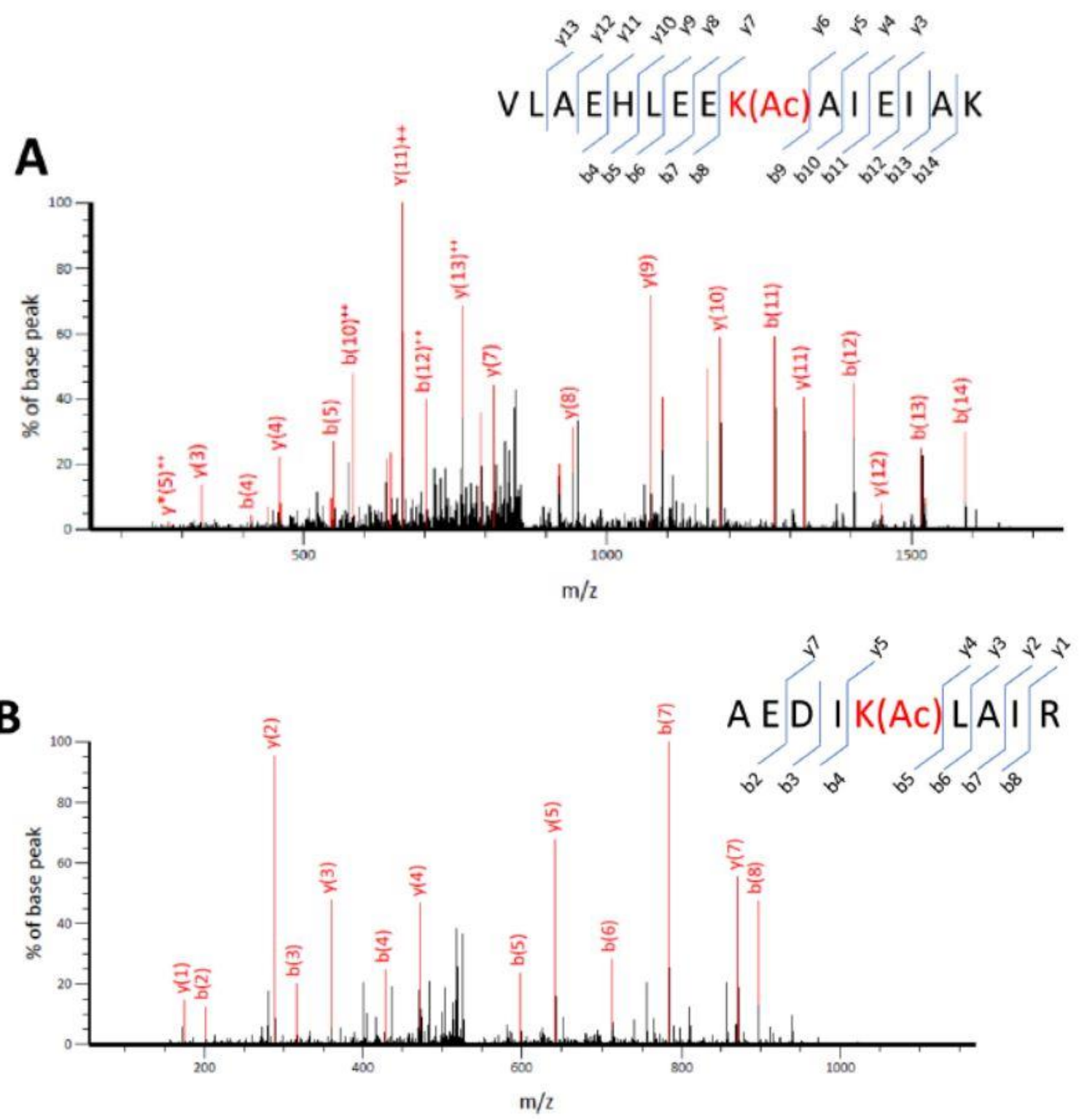




\section{Figure 6}

Position of the acetylation sites found in the 4 histone proteins. On the multi-alignment of the histones A and B sequences from T. gammatolerans $(\mathrm{Tg})$ and T. kodakaraensis (Tk) the conserved and not conserved lysines $(\mathrm{K})$ are indicated with red and grey arrows, respectively. The N-terminal acetylation position is illustrated by a yellow arrow. Acetylated lysine from peptides trapped by antibodies by colored in blue. Acetylated lysines detected from chromatin enriched histones are colored in green. (For interpretation of the references to colour in this fig. legend, the reader is referred to the web version of this article.)

Tg Histone A Tg Histone B

TK Histone A

TK Histone B

Consensus

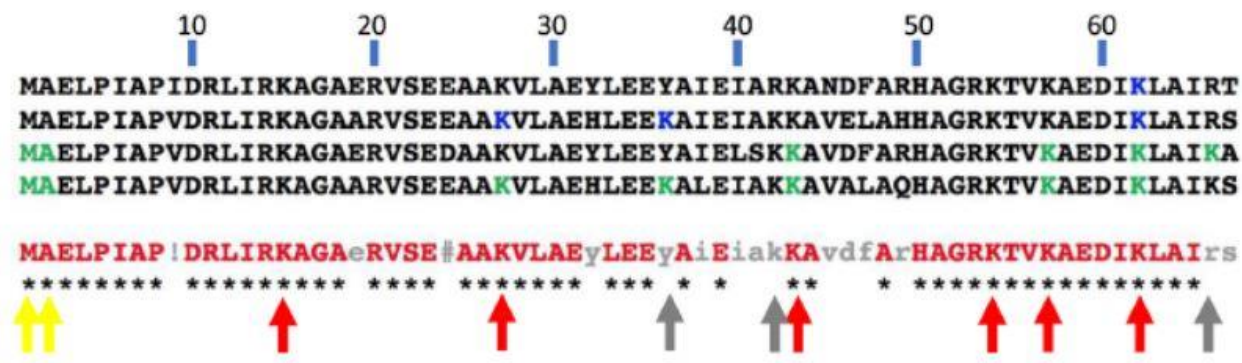




\section{Figure 7}

Interactions between TkHB dimers in the hypernucleosome model. The $\mathrm{i}+2$ dimer interactions involving K26, K61 and K65 are highlighted (white box). Each dimer is colored differently and represented in cartoon. Lysines 26, 61 and 65 in dimers 2 and 3 are represented in blue sticks while glutamates 30,34 and 58 in dimers 1 and 4 are represented in red sticks. (For interpretation of the references to colour in this fig. legend, the reader is referred to the web version of this article.)

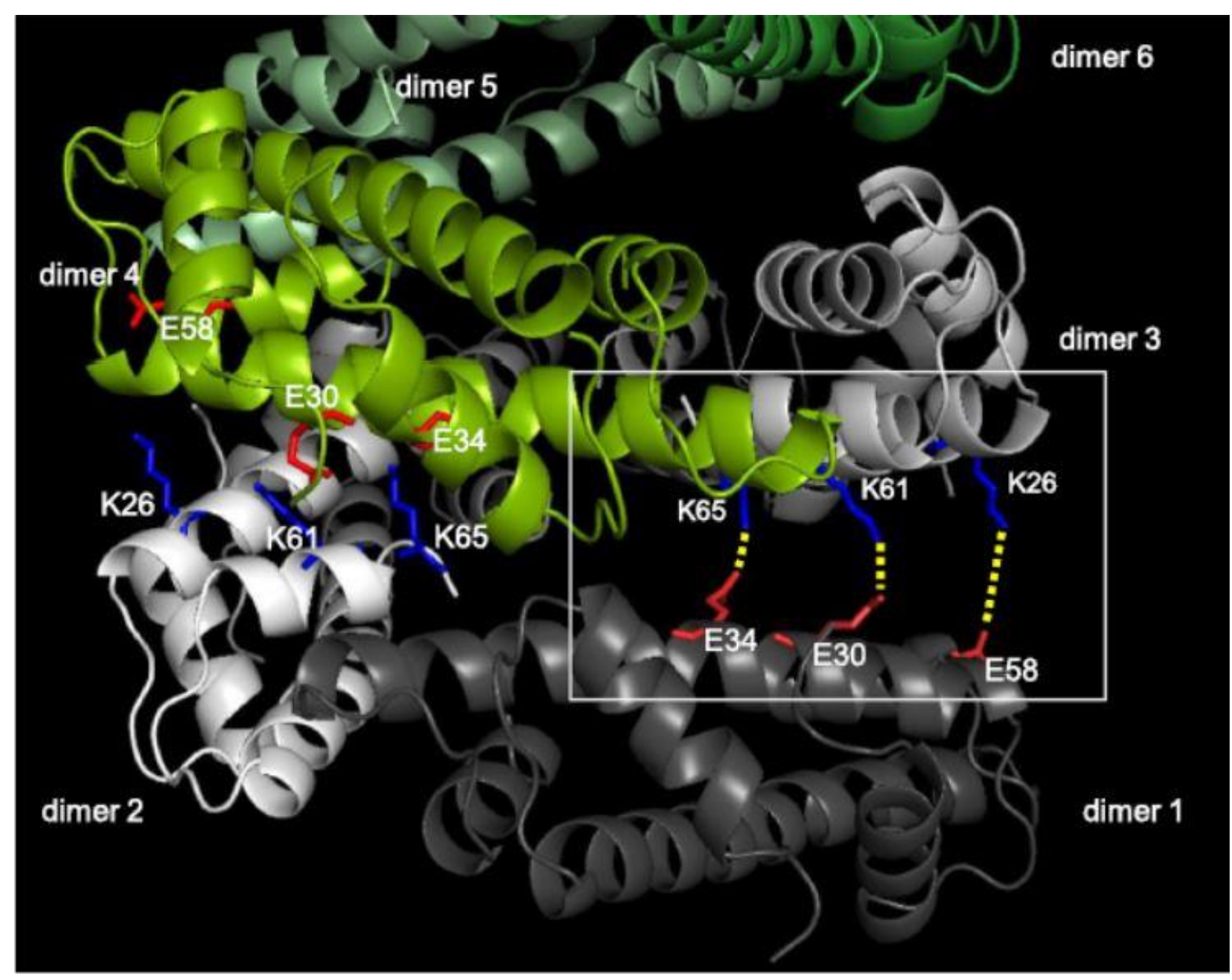

